\title{
Optimal Design Method for Absorption Heat Pump Cycles Based on Energy-Utilization Diagram
}

\author{
K. Seki ${ }^{1 *}$, H. Hattori ${ }^{2}$, Y. Amano ${ }^{3}$ \\ ${ }^{1,2}$ Department of Applied Mechanics Waseda University, Tokyo, Japan. \\ ${ }^{3}$ Department of Applied Mechanics and Aerospace Engineering, Waseda university \\ E-mail: ${ }^{1}$ k_seki@ power.mech.waseda.ac.jp, ${ }^{2}$ h_hattori@ power.mech.waseda.ac.jp, ${ }^{3}$ yoshiha@waseda.jp
}

Received 19 December 2018, Revised 17 February 2019, Accepted 17 February 2019

\begin{abstract}
Optimization for energy systems is considered at three levels: synthesis (configuration), design (component characteristics), and operation. The objective of this paper is to propose a method to perform design/operation optimization efficiently based on an energy-utilization diagram (EUD) for performance improvement. Before optimization, this paper evaluates the system performance and margins for improvement of two absorption heat pumps, including an absorber heat exchanger (AHX) and a solution heat exchanger (SHX). Then, exergy efficiency is higher in the SHX cycle, while the margin for improvement is larger in the AHX cycle. The optimization attempts to reduce exergy destruction in the components where dominant exergy destruction caused by heat transfer occurs. The operating points are adjusted to make the temperature gradients at hot and cold sides coincide. The design parameters in other components are adjusted to improve the heat transfer performances. The distribution of exergy destruction of each component leads to improve exergy efficiency. After these improvements, exergy efficiency is higher in the AHX cycle. It is concluded that we could efficiently realize the design/operation optimization of thermodynamic systems using an EUD, which presents both exergy destruction and margin for improvement at the components comprehensively, as well as operating properties of working fluids.
\end{abstract}

Keywords: Optimal design; absorption heat pump system; exergy analysis; energy-utilization diagram.

\section{Introduction}

Absorption chillers and heat pumps using ammonia as the working fluid, which use renewable energy or recovered exhaust heat, have been recently studied. The most significant feature of an absorption heat pump is the use of a heat source as the main driving source. For example, engineers have developed the absorption systems operating by utilizing solar, geothermal, and biomass energy, and recover waste heat from an engine [1-4]. And several types of absorption cycles have been proposed, e.g. the absorber heat exchanger (AHX) cycle [5] and the generator absorber heat exchanger (GAX) cycle [6]. In addition, several studies attempt to raise the absorber pressure by compressor or ejector [7-8].

An optimal design method for these absorption heat pump systems is important for a rational use of natural and economic resources. Optimization is considered at three levels: synthesis, design, and operation [9]. At the synthesis level, a general criterion to define a cycle configuration of energy systems with absorption technology has been proposed [10]. In addition, an effective method to decide the optimal number of generators in an absorption heat pump cycle for the specific heat source temperature is proposed [11]. At the design and operation levels, only parametric or heuristic studies have been conducted so far for improving cycle performance [12], because it is difficult to perform optimization of design and operation for the absorption heat pump systems that have several design parameters.
Considering this background, this study aims to propose a method for realizing the optimal design of absorption heat pumps using an energy-utilization diagram (EUD).

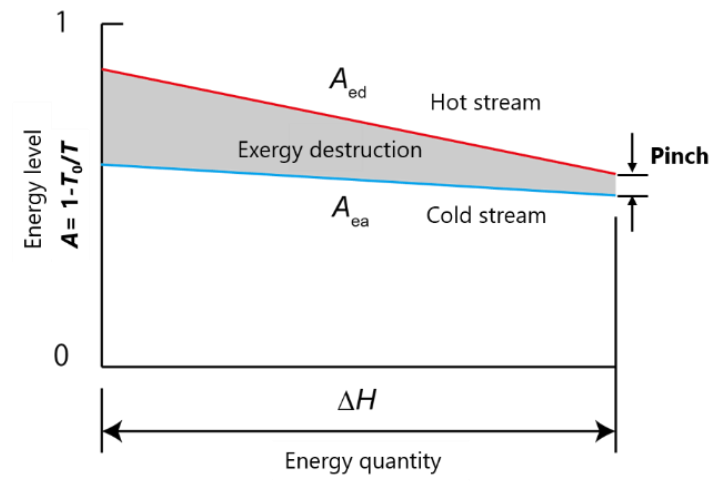

Figure 1. Energy Utilization Diagram.

An EUD is a graphical method for describing the exergy destructions in industrial processes, i.e., improving exergy use [13]. The EUD is represented by plotting the energy level against energy quantity as shown in Figure 1. EUD gives us information about the three contents.

1) Exergy destruction rate in each component: the rate equals the area between the hot and cold curves.

2) Margin for reduction of exergy destruction: the information is obtained by looking energy level difference between the hot and cold curves at the pinch point. 
3) Temperature profile in each component: as for heat exchangers network, energy level and temperature of each working fluid are in one-to-one correspondence.

The EUD is useful for evaluating system performances because it presents not only exergy destruction but also margin for improvement. In previous studies using EUD, system evaluations have been performed on the basis of an EUD [14-15], but an EUD has not been used for an actual optimal design.

This paper first evaluates two existing absorption heat pump cycles - an absorber heat exchanger (AHX) cycle and a solution heat exchanger (SHX) cycle - using an EUD [16]. Then, the cycle model of each heat pump with AHX and SHX cycles is constructed. This model comprises a pump, expansion valves, and heat exchangers, which are shell-andtube type. The model parameters required to represent the thermodynamic and geometric characteristics are determined from an experimental study that we conduct using a commercial gas-fired absorption heat pump. A cycle simulation is performed, and the result indicates the dominant location of irreversibility and operability. This study considers exergy destruction from two components: one associated with the frictional pressure drop and the other including heat transfer in each heat exchanger. This study evaluates the exergy loss caused by heat transfer in each component by using an EUD and compares the EUDs of AHX and SHX cycles. Then, an optimal design for these cycles is developed based on the EUDs. The operating point and design parameters of some components in these cycles are changed for improving the cycle performance. After that, cycle simulations are repeated to confirm and evaluate the improvement effects, and the performance of the designed heat pump is evaluated using COP and exergy efficiency. This study reveals that the method for designing a heat pump using an EUD is effective for the optimization of a heat pump.

\section{Methodology}

The flow of the optimal design method for the absorption heat pump is shown in Figure 2. First, the models of the AHX and SHX cycles are developed, which consider exergy destruction caused by heat transfer and pressure loss. The input parameters for the cycle models and the heat exchanger design parameters, which decide the system operation point, are decided based on the experimental result of a commercial absorption heat pump. Next, cycle simulation and exergy analysis are performed to evaluate the system performance and identify the components where dominant exergy destruction occurs. In addition, EUDs of these two heat pump cycles are drawn to evaluate margins for improvement. Based on these EUDs, the operating point is changed and the effective design parameters for optimization are identified. The operating points are improved by changing the temperature conditions of the external fluids to make the temperature gradients of the hot and cold sides coincide in the heat exchangers. Subsequently, the design parameters of dominant heat exchangers are improved. In this step, the heat transfer area and the number of heat transfer tubes are fixed, while the diameter and length of the heat transfer tube are varied. Finally, the exergy analysis is performed again. By repeating the procedure, a reduction in exergy destruction for the heat pump cycle is obtained. We then compare the EUDs of the designed heat pumps and evaluate the system performance. In this study, COP and exergy efficiency are considered the factors for evaluating system performance.

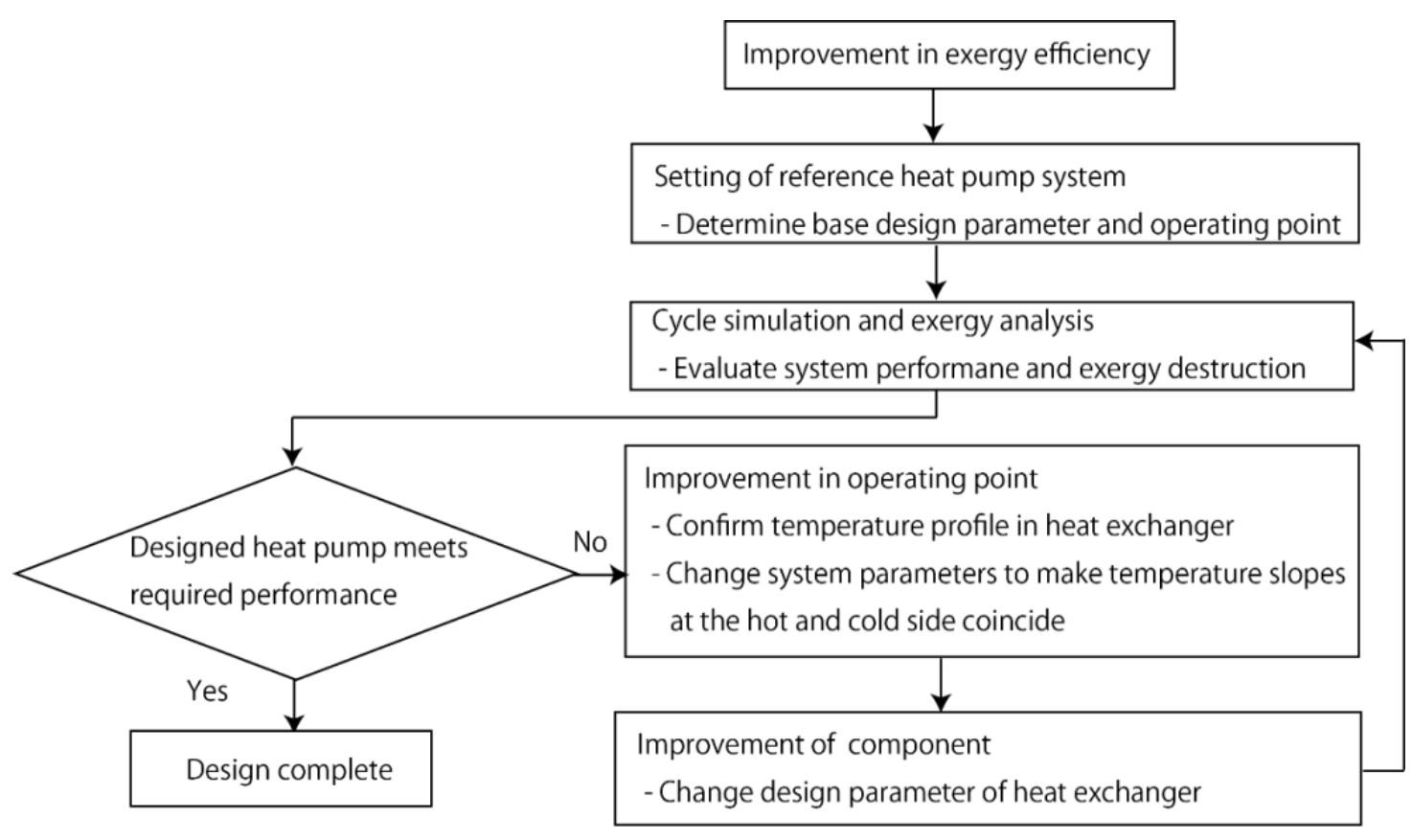

Figure 2. Optimal design flow of an absorption heat pump system. 


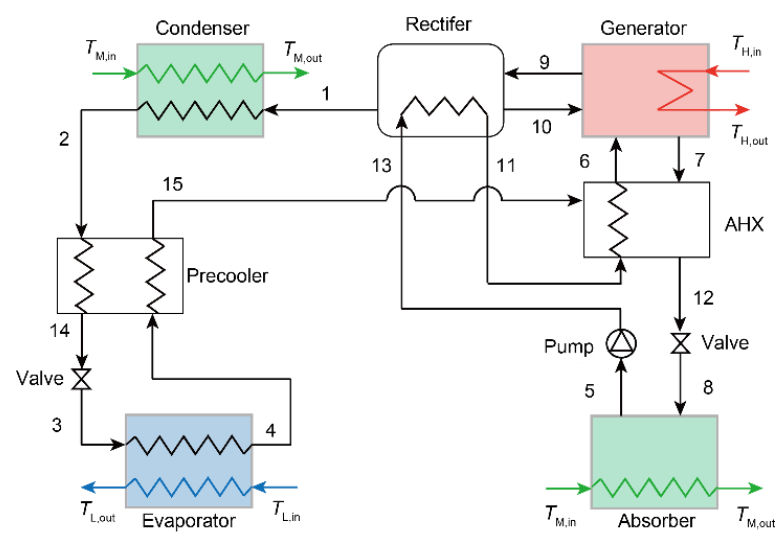

(a) Schematic of AHX cycle.

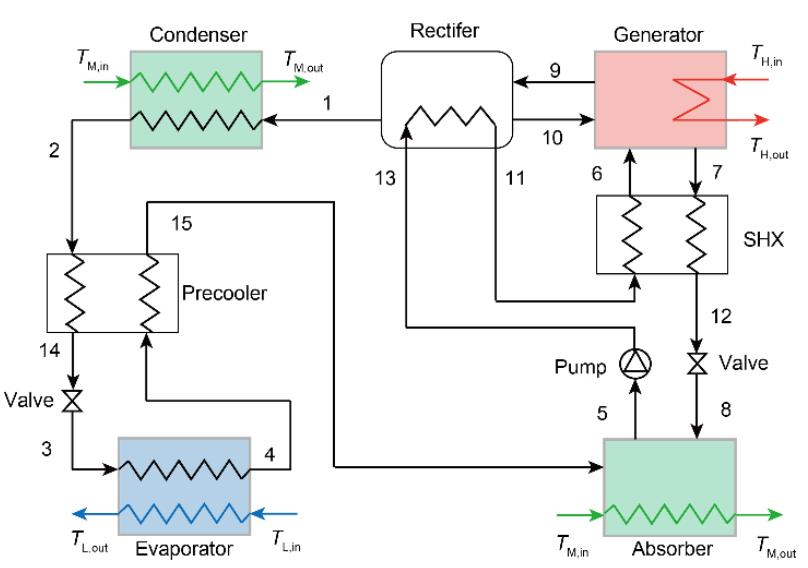

(b) Schematic of SHX cycle.

Figure 3. Schematic of the absorption heat pump cycles (Figure is in color in the on-line version of the paper).

Table 1. Setting values at the design point.

\begin{tabular}{|c|c|c|c|}
\hline \multicolumn{3}{|l|}{ Input parameter } & \multirow{2}{*}{$\begin{array}{l}\text { Values } \\
120\end{array}$} \\
\hline Generator heat source inlet temperature & $T_{\mathrm{H}, \mathrm{in}}$ & ${ }^{\circ} \mathrm{C}$ & \\
\hline Generator heat source outlet temperature & $T_{\mathrm{H}, \mathrm{out}}$ & ${ }^{\circ} \mathrm{C}$ & $T_{\mathrm{H}, \mathrm{in}}-5$ \\
\hline Condenser and absorber hot water inlet temperature & $T_{\mathrm{M}, \mathrm{in}}$ & ${ }^{\circ} \mathrm{C}$ & $T_{\mathrm{M}, \text { out }}-10$ \\
\hline Condenser and absorber hot water outlet temperature & $T_{\mathrm{M}, \text { out }}$ & ${ }^{\circ} \mathrm{C}$ & 45 \\
\hline Evaporator brine inlet temperature & $T_{\mathrm{L}, \text { in }}$ & ${ }^{\circ} \mathrm{C}$ & 23 \\
\hline Evaporator brine outlet temperature & $T_{\mathrm{L}, \text { out }}$ & ${ }^{\circ} \mathrm{C}$ & -5 \\
\hline Ambient pressure & $P_{0}$ & MPa.a & 0.1013 \\
\hline Heat source hot water pressure & $P_{\mathrm{H}}$ & MPa.a & 0.1013 \\
\hline Condenser hot water pressure & $P_{\mathrm{M}}$ & MPa.a & 0.1013 \\
\hline Evaporator brine pressure & $P_{\mathrm{L}}$ & MPa.a & 0.1013 \\
\hline Refrigerant mass fraction & $Z_{\mathrm{NH3}}$ & $\mathrm{NH}_{3} \mathrm{~kg} / \mathrm{kg}$ & 0.998 \\
\hline Mass fraction of evaporator brine & $Z_{\text {brine }}$ & $\mathrm{CH} 3 \mathrm{OHkg} / \mathrm{kg}$ & 0.25 \\
\hline Quantity of heat source & $Q_{\mathrm{GEN}}$ & $\mathrm{kW}$ & 25 \\
\hline Condenser inlet quality & $Q u_{1}$ & - & 1 \\
\hline Condenser outlet quality & $Q u_{2}$ & - & 0 \\
\hline Evaporator outlet quality & $Q u_{6}$ & - & 0.99 \\
\hline Generator outlet quality of solution & $Q u_{8}$ & - & 0 \\
\hline Absorber outlet quality & $Q u_{11}$ & - & 0 \\
\hline Rectifier inlet quality & $Q u_{15}$ & - & 1 \\
\hline Rectifier outlet quality & $Q u_{16}$ & - & 0 \\
\hline Precooler outlet degree of subcooling & $\Delta T_{\mathrm{sC}, 4}$ & ${ }^{\circ} \mathrm{C}$ & 1 \\
\hline Condenser pinch point temperature difference & $\Delta T_{\text {pinch,CON }}$ & ${ }^{\circ} \mathrm{C}$ & 5 \\
\hline Absorber pinch point temperature difference & $\Delta T_{\text {pinch,ABS }}$ & ${ }^{\circ} \mathrm{C}$ & 5 \\
\hline Evaporator pinch point temperature difference & $\Delta T_{\text {pinch,EVA }}$ & ${ }^{\circ} \mathrm{C}$ & 5 \\
\hline AHX pinch point temperature difference & $\Delta T_{\text {pinch,AHX }}$ & ${ }^{\circ} \mathrm{C}$ & 5 \\
\hline SHX pinch point temperature difference & $\Delta T_{\text {pinch,SHX }}$ & ${ }^{\circ} \mathrm{C}$ & 5 \\
\hline Precooler approach temperature difference $\left(=T_{3}-T_{7}\right)$ & $\Delta T_{\mathrm{PRC}}$ & ${ }^{\circ} \mathrm{C}$ & 5 \\
\hline Generator approach temperature difference $\left(=T_{\mathrm{H}, \mathrm{in}}-T_{8}\right)$ & $\Delta T_{\mathrm{GEN}}$ & ${ }^{\circ} \mathrm{C}$ & 10 \\
\hline Pump efficiency & $\eta_{\mathrm{p}}$ & - & 0.8 \\
\hline Rectifying efficiency & $\eta_{\mathrm{R}}$ & - & 0.8 \\
\hline
\end{tabular}

\section{Cycle Description and Assumptions}

A schematic of an AHX cycle with an ammonia-water mixture is shown in Figure 3(a). The system comprises nine components: generator, condenser, precooler, evaporator, absorber, AHX, rectifier, solution heat pump, and expansion valve. In the generator, high-pressure vapor, assumed as the waste heat generated from a gas engine at $120^{\circ} \mathrm{C}$, can be created by the heat source. The system aims at improving the $\mathrm{COP}$ by recovering the heat generated when a weak solution absorbs a strong vapor in the AHX. The basic operation of the system is as follows: the vapor leaving the generator is concentrated by the rectifier and condensed in the condenser in the process of rejecting heat to the environment. The strong solution moves to the evaporator through the precooler. Then, the refrigerant vapor from the evaporator and the weak solution from the generator, which has been expanded by the expansion valve, are mixed in the AHX. The solution leaving the AHX is 
condensed in the absorber, rejecting heat to the outside, and then raised to the same pressure as in the generator by the solution pump. The high-pressure solution returns to the generator, restoring condensation heat in the rectifier and absorption heat in the AHX. Figure 3(b) shows a schematic of a SHX cycle. In this system, instead of the AHX, SHX is installed at the absorber inlet.

In this study, we design an absorption heat pump to be used in agricultural facilities. Thus, the temperature condition is different from heating ventilating air conditioning, as given in Table 1. For the cycle simulation, the following assumptions are made:

1.The heat pump system reaches a steady state.

2.The pressure drop in pipes and heat losses to the environment in the components are neglected.

3.The flow through the expansion valve is isenthalpic.

4.The density and mass flow rate do not change between the inlet and outlet of the heat exchanger.

5.The heat exchangers do not exchange heat with the surroundings.

\section{Modeling of the Absorption Heat Pump Cycles}

Here, we describe a method for constructing a model of the absorption heat pump system using an ammonia-water mixture. The cycle model is constructed by assembling the calculation models of all components. The calculation model of each component is described as follows.

The heat exchangers are shell-and-tube type and are countercurrent ones. They are characterized by an overall heat transfer coefficient $U$, heat transfer area $A$, and mean logarithmic temperature difference $\Delta T_{\mathrm{lm}}$. The heat transfer equations for each component are as in the Eqs. (1)-(4).

$$
\dot{Q}=U A \Delta T_{\mathrm{lm}}
$$

$$
U=\frac{1}{\frac{d_{\text {out }}}{d_{\text {in }}}+\frac{r_{\text {in }} d_{\text {out }}}{d_{\text {in }}}+\frac{d_{\text {out }}}{2 k_{\text {tube }}} \cdot \ln \left(\frac{d_{\text {out }}}{d_{\text {in }}}\right)+r_{\text {out }}+\frac{1}{\alpha_{\text {out }}}}
$$

$$
A=\pi d_{\text {out }} L N
$$

$$
\Delta T_{\mathrm{lm}}=\frac{\left(T_{\mathrm{h}, \mathrm{i}}-T_{\mathrm{c}, \mathrm{o}}\right)-\left(T_{\mathrm{h}, \mathrm{o}}-T_{\mathrm{c}, \mathrm{i}}\right)}{\ln \frac{T_{\mathrm{h}, \mathrm{i}}-T_{\mathrm{c}, \mathrm{o}}}{T_{\mathrm{h}, \mathrm{o}}-T_{\mathrm{c}, \mathrm{i}}}}
$$

In the equation (2), the symbols $d_{\text {in }} / d_{\text {out }}$ represent the internal/external diameter of each tube, and $r_{\text {in }} / r_{\text {out }}$ indicate the fouling factor of the internal/external fluid, and $k$ represents the thermal conductivity. In the equation (3), $L / N$ indicates the length/number of each tube. In the equation (4), the subscripts $\mathrm{h} / \mathrm{c}$ represent the hot/cold thermal stream and i/o represent the inlet/outlet of each heat exchanger.

In the condenser and absorber, the heat transfer coefficient for hot water is calculated as in the Eq. (5) using Short correlation [17].

$$
\alpha_{\text {out }}=\frac{0.16 R e_{\text {out }}^{0.6} P r_{\text {out }}^{0.33} k_{\text {out }}}{d_{\text {out }}}
$$

$$
\left(200<R e_{\text {out }}<20,000\right)
$$

The heat transfer coefficient for the condensate is calculated as in the Eq. (6) using Carpenter's film condensation correlation [17].

$$
\begin{aligned}
\alpha_{\mathrm{CON}, \mathrm{in}}=0.065 \cdot\left(\frac{c_{\mathrm{p}, \mathrm{in}, 1} \cdot \rho_{\mathrm{in}, 1} \cdot k_{\mathrm{in}} \cdot f_{\mathrm{in}}}{2 \mu_{\mathrm{in}} \cdot \rho_{\mathrm{in}, \mathrm{v}}}\right)^{0.5} \cdot G_{\mathrm{in}} \\
\left(6.7 \mathrm{~kg} / \mathrm{m}^{2}<\frac{f_{\mathrm{in}} \cdot G_{\mathrm{in}}^{2}}{2 g \cdot \rho_{\mathrm{v}}}<360 \mathrm{~kg} / \mathrm{m}^{2}\right)
\end{aligned}
$$

In the equation, the symbols $\rho_{\mathrm{in}, \mathrm{l}} / \rho_{\mathrm{in}, \mathrm{v}}$ represent the density of the liquid/ vapor in the internal fluid, and $c_{\mathrm{p}, \mathrm{in}, \mathrm{l}}$ represents the specific heat at constant pressure of the liquid in the internal fluid, and $\mu_{\text {in }}$ indicates the viscosity, and $G_{\text {in }}$ means the mass velocity of the internal fluid.

In the evaporator, the heat transfer coefficient for brine is calculated using Short correlation, as shown in the Eq. (5), and that for evaporation is calculated as in the Eq. (7) using Gilmour correlation [17].

$$
\begin{aligned}
\alpha_{\mathrm{EVA}, \mathrm{in}}=0.00059 \cdot c_{\mathrm{p}, \mathrm{in}} \cdot G_{\mathrm{in}} \cdot P r_{\mathrm{in}}^{-0.6} \cdot R e_{\mathrm{in}}^{-0.3} \cdot & \left(\frac{\rho_{\mathrm{in}, 1} \cdot \sigma_{\mathrm{EVA}, \mathrm{in}}}{P_{\mathrm{in}}^{2}}\right)^{-0.425} \\
& \left(10^{2}<R e_{\mathrm{in}}<10^{6}\right)
\end{aligned}
$$

In the equation, $\sigma$ means the surface tension of the substance, $P$ indicates the pressure of substances.

In the AHX, the heat transfer coefficient for the shell side is calculated as in the Eq. (8) using Hoffman correlation [17].

$$
\alpha_{\mathrm{AHX}, \text { out }}=0.205 \cdot\left(\frac{B^{0.38}}{d_{\text {out }}^{0.535}}\right)\left(\frac{3.4 c_{\mathrm{p}, \text { out }}^{0.535} r_{\text {out }}^{0.31} k_{\text {out }}^{0.46}}{\left(\frac{\mu_{\text {out }}}{g}\right)^{0.155}}\right){ }_{\left(R e_{\text {out }}<1,600\right)}
$$

In the equation, $B$ means mass flow rate of dilute solution sprayed from the top of the shell, and $g$ represents the gravitational acceleration.

The heat transfer coefficient for the inside tube is calculated as in the Eq. (9) using Hausen correlation [17].

$$
\begin{aligned}
& \alpha_{\mathrm{AHX}, \mathrm{in}} \\
& =\frac{0.116\left(R e_{\mathrm{in}}^{0.66}-125\right) \cdot P r_{\mathrm{in}}^{0.33} \cdot\left(1+\left(\frac{d_{\mathrm{in}}}{L}\right)^{0.66}\right) k_{\mathrm{in}}}{d_{\mathrm{in}}} \\
& \left(2,320<R e_{\text {in }}>100,000,0.6<P r_{\text {in }}<500, \frac{L}{d_{\text {in }}} \geq 1\right)
\end{aligned}
$$

In the SHX, the heat transfer coefficient for the shell side is calculated using Short correlation, as shown in Eq. (5), and that for the inside tube is calculated as in the Eq. (10) using Hausen correlation [17].

$$
\begin{aligned}
& \alpha_{\mathrm{SHX}, \mathrm{in}} \\
& =\frac{0.116\left(R e_{\mathrm{in}}^{0.66}-125\right) \cdot P r_{\mathrm{in}}^{0.33} \cdot\left(1+\left(\frac{d_{\mathrm{in}}}{L}\right)^{0.66}\right) k_{\mathrm{in}}}{d_{\mathrm{in}}} \\
& \left(2,320<R e_{\text {in }}>100,000,0.6<P r_{\text {in }}<500, \frac{L}{d_{\text {in }}} \geq 1\right)
\end{aligned}
$$

In the generator, the heat transfer coefficient for the refrigerant solution is calculated as in the Eq. (11) using Bromey’s film boiling correlation [17]. 


$$
\begin{aligned}
& \alpha_{\mathrm{GEN}, \text { out }} \\
& =0.62\left(\frac{1}{d_{\text {out }}}\right)^{0.25}\left(\frac{k_{\text {out },}^{3} \rho_{\text {out }, \mathrm{v}}\left(\rho_{\text {out }, 1}-\rho_{\text {out }, \mathrm{v}}\right) g \lambda_{\text {out }}}{\Delta T \mu_{\text {out }}}\right)^{0.25}
\end{aligned}
$$

$\left(800<R e_{\text {out }}<5,000\right)$

In the equation, $\lambda$ represents the vaporization heat of the refrigerant, and $\Delta T$ indicates the difference between temperature of tube wall and temperature of the refrigerant. The heat transfer coefficient for the water side is calculated as in the Eq. (12) using Sieder correlation [17].

$$
\begin{aligned}
\alpha_{\mathrm{GEN}, \mathrm{in}}=\frac{0.023 \operatorname{Re}_{\mathrm{in}}^{0.8} P r_{\mathrm{in}}^{0.4} k_{\mathrm{in}}}{d_{\mathrm{in}}} \\
\left(R e_{\mathrm{in}}>10,000,0.7<P r_{\mathrm{in}}<16,700, \frac{L}{d_{\text {in }}}>60\right)
\end{aligned}
$$

In the rectifier, the heat transfer coefficient for the shell side is calculated as in the Eq. (13) using Nusselt film condensation correlation [17].

$$
\alpha_{\mathrm{REC}, \text { out }}=0.725\left(\frac{k_{\text {ou }}^{3} \rho_{\text {out }}^{2} \lambda_{\text {out }} g}{\mu_{\text {out }} d_{\text {out }} \Delta T_{\text {out }}}\right)^{0.25} \cdot N_{\text {pass }}^{0.25}
$$

$$
\left(\operatorname{Re}_{\text {out }}<2,100\right)
$$

In the equation, $N_{\text {pass }}$ means the pass number of the tube. The heat transfer coefficient for the inside tube is calculated using Hausen correlation.

This study considers the pressure loss of each component in the cycle. The pressure losses of the inside and outside tube in the heat exchangers of shell-and-tube type are calculated using the following equation [17]:

The pressure loss caused by friction is as in the Eq. (14).

$$
\Delta P_{\mathrm{f}}=\frac{4 f G L}{2 \rho d} \times N
$$

$$
\begin{aligned}
& \text { If } R e=\frac{d G}{\mu}<2000, \quad f=\frac{16}{R e} \text { and } \\
& \text { If } R e=\frac{d G}{\mu}>2000 \quad, \quad f=0.00140+\frac{0.125}{R e^{0.32}}
\end{aligned}
$$

The geometric parameters of each component are determined from an experimental study conducted using a commercial gas-fired absorption heat pump. The specifications of each component in the AHX and SHX cycles are given in Table 2.

\section{Evaluation Criteria}

In this study, the exergy evaluation caused by heat transfer is performed based on an EUD. The availability factor $A$ indicates the quality of energy transferred from and into the system and can be expressed as in the Eq. (17) [13].

$$
A=\frac{\Delta E}{\Delta H}
$$

In the equation, $\Delta H$ represents the energy transfer rate, while $\Delta E$ indicates the exergy transfer rate.

In heat exchangers, the energy level $A$ is calculated as shown in the Eq. (18).

$$
A=1-\frac{T_{0}}{T}
$$

\begin{tabular}{|c|c|c|c|c|c|c|c|c|c|c|}
\hline \multirow{2}{*}{\multicolumn{5}{|c|}{ Specification }} & \multirow{3}{*}{$\begin{array}{c}\text { ABS } \\
202\end{array}$} & \multirow{3}{*}{$\begin{array}{c}\text { CON } \\
202\end{array}$} & \multirow{3}{*}{$\begin{array}{c}\text { EVA } \\
229\end{array}$} & \multirow{3}{*}{\multicolumn{2}{|c|}{$\begin{array}{c}\text { AHX } \\
/ \\
\text { SHX } \\
111\end{array}$}} & \multirow{3}{*}{$\begin{array}{c}\text { PRC } \\
19.8\end{array}$} \\
\hline & & & & & & & & & & \\
\hline \multirow{7}{*}{$\begin{array}{l}\text { AHX } \\
\text { cycle }\end{array}$} & \multirow{3}{*}{ Shell } & \multirow{3}{*}{ Size } & $W$ & $\mathrm{~mm}$ & & & & & & \\
\hline & & & $D$ & $\mathrm{~mm}$ & 202 & 147 & 311 & 100 & 111 & 837 \\
\hline & & & $H$ & $\mathrm{~mm}$ & 1313 & 1045 & 780 & 110 & 942 & - \\
\hline & \multirow{4}{*}{ Tube } & Tube size & $d$ & $\mathrm{~mm}$ & 15 & 15 & 15 & 15 & 15 & 15 \\
\hline & & Tube thickness & $t$ & $\mathrm{~mm}$ & 1.2 & 1.2 & 1.2 & 1.2 & 1.2 & 1.2 \\
\hline & & Number of tubes & $N$ & - & 5 & 10 & 8 & 1 & 1 & 1 \\
\hline & & Number of paths & $N_{\text {pass }}$ & - & 7 & 10 & 8 & 5 & 53 & 53 \\
\hline \multirow{7}{*}{$\begin{array}{l}\text { SHX } \\
\text { cycle }\end{array}$} & \multirow{3}{*}{ Shell } & & $W$ & $\mathrm{~mm}$ & 284 & 202 & 229 & 227 & 202 & 19.8 \\
\hline & & Size & $D$ & $\mathrm{~mm}$ & 284 & 147 & 229 & 100 & 147 & 1202 \\
\hline & & & $H$ & $\mathrm{~mm}$ & 1294 & 1107 & 997 & 110 & 1214 & - \\
\hline & \multirow{4}{*}{ Tube } & Tube size & $D$ & $\mathrm{~mm}$ & 15 & 15 & 15 & 15 & 15 & 15 \\
\hline & & Tube thickness & $T$ & $\mathrm{~mm}$ & 1.2 & 1.2 & 1.2 & 1.2 & 1.2 & 1.2 \\
\hline & & Number of tubes & $N$ & - & 10 & 5 & 8 & 1 & 5 & 1 \\
\hline & & Number of paths & $N_{\text {pass }}$ & - & 10 & 7 & 8 & 5 & 7 & 20 \\
\hline
\end{tabular}

In the EUD, the horizontal axis indicates the quantity of energy and the vertical axis indicates the quality of energy. The factor $A$ at the hot side $\left(A_{\text {ed }}\right)$ and that at the cold side $\left(A_{\text {ea }}\right)$ are plotted. Exergy destruction caused by heat transfer is calculated as in the Eq. (19).

$$
E_{\mathrm{D}, \mathrm{HT}}=\sum \Delta H\left(A_{\text {ed }}-A_{\text {ea }}\right)
$$

The friction factor $f$ is calculated as in the Eqs. (15), (16).

Table 2. Specifications of components in the reference system of AHX and SHX cycles

Eq. (19) shows exergy destruction caused by heat transfer as the area between $A_{\text {ed }}$ and $A_{\text {ea }}$, and the difference between
$A_{\text {ed }}$ and $A_{\text {ea }}$ indicates the driving force of heat transfer. The difference at the pinch point indicates the margin for 
reduction of exergy destruction by adjusting the design parameters. In addition, the exergy destruction caused by pressure loss is evaluated, and can be expressed as in the Eq. (20).

$$
E_{\mathrm{D}, \mathrm{PL}}=T_{0}\left(\frac{\dot{m} v_{\mathrm{in}} \Delta P}{T}\right)
$$

In the equation, $v_{\text {in }}$ represents the specific volume of the working fluid.

To evaluate the performance of the designed ejectorabsorption heat pump, the modified COP and exergy efficiency are defined as in the Eqs. (21), (22).

$$
\begin{aligned}
& C O P=\frac{\dot{Q}_{\mathrm{CON}}+\dot{Q}_{\mathrm{ABS}}}{\dot{Q}_{\mathrm{GEN}}+\dot{W}_{\mathrm{P}}} \\
& \eta_{\mathrm{ex}}=\frac{\sum\left(\Delta H_{\mathrm{ea}}^{\mathrm{CON}} A_{\mathrm{ea}}^{\mathrm{CON}}+\Delta H_{\mathrm{ea}}^{\mathrm{ABS}} A_{\mathrm{ea}}^{\mathrm{ABS}}\right)}{\sum\left(\Delta H_{\mathrm{ea}}^{\mathrm{GEN}} A_{\mathrm{ed}}^{\mathrm{GEN}}\right)+\dot{W}_{\mathrm{P}}}
\end{aligned}
$$

\section{Results}

\subsection{Evaluation of the Reference Systems}

The exergy analysis results of the reference systems are as follows. The exergy destruction caused by heat transfer and pressure loss in each component in the AHX and SHX cycles are shown in Figures 4 and 6, respectively. Exergy destruction caused by heat transfer is larger than that caused by pressure loss in all heat exchangers; the EUDs (heat exchange system) are shown in Figures 5 and 7 . For the AHX cycle, the COP of the reference system is 1.60 and the exergy efficiency is 0.32 , while for the SHX cycle, the COP of the reference system is 1.72 and the exergy efficiency is 0.34. Thus, the COP and the exergy efficiency are higher for the SHX cycle. However, the EUDs represent that the improvement margin is larger for the AHX cycle. For the AHX cycle, according to Figure 5, the difference between $A_{\text {ed }}$ and $A_{\text {ea }}$ is especially large in the absorber because the difference in the temperature gradients at both sides is large. For the SHX cycle, as indicated in Figure 7, there is no point where the difference between $A_{\text {ed }}$ and $A_{\text {ea }}$ is especially large, because the total heat duty is larger and temperature gradients at the hot and cold sides are almost the same in all components. The components where dominant exergy destruction occurs are absorber, evaporator, and condenser in order from the larger for the AHX cycle, while for the SHX cycle, the components are evaporator, condenser, absorber, and SHX.

\subsection{Improvements in Operating Properties of Working Fluids and Component Characteristics}

In the AHX cycle, dominant exergy destruction occurs and the difference in temperature gradients at the hot and cold sides reduces the margin for reduction. Then, the temperature gradients are made to coincide with each other by adjusting the hot water outlet temperature in the absorber, $T_{\mathrm{ABS} \text {,out }}$. In view of the requirement that $A_{\mathrm{ed}}$ is larger than $A_{\text {ea }}$ at the pinch point, we determine the system parameters as follows. The hot water outlet temperature in the absorber, $T_{\mathrm{ABS} \text {,out }}$, is $60{ }^{\circ} \mathrm{C}$, while that in the condenser, $T_{\mathrm{CON}, \text { out }}$, is $40^{\circ} \mathrm{C}$. Figures 8 and 9 show the results of exergy analysis after improvement. The COP is 1.60 , which is the same as that in the reference system, and the exergy efficiency is 0.39 , which is $22 \%$ higher than that in the reference system.

According to Figure 8, exergy destruction in the absorber is decreased by $49 \%$. As shown in Figure 9, the temperature gradients at the hot and cold sides are made to coincide with each other by improving the operating point. In the AHX cycle, according to Figure 8, the components where dominant exergy destruction occurs are condenser and evaporator. Then, the design parameters in the condenser are adjusted to improve the heat transfer performance. In this step, the heat transfer area and the number of heat transfer tubes are kept fixed, while the diameter and length of the heat transfer tube are varied. At the optimal design point, the heat transfer tube has a diameter of $13 \mathrm{~mm}$. After that, the design parameters in the evaporator are adjusted to improve the heat transfer performance. At the optimal design point, the heat transfer tube has a diameter of $9 \mathrm{~mm}$.

In the SHX cycle, according to Figure 6, the component where dominant exergy destruction occurs is evaporator. Then, the design parameters in the evaporator are adjusted to improve the heat transfer performance. At the optimal design point, the heat transfer tube has a diameter of $5 \mathrm{~mm}$. Then, the exergy analysis results at the design point represents that the component where dominant exergy destruction occurs is condenser. Hence, the design parameters required to improve the heat transfer performance in the condenser are adjusted. At the optimal point, the heat transfer tube has a diameter of $14.5 \mathrm{~mm}$.

Figures 10-13 show the results of exergy analysis before and after improvements in the two cycles. In addition, the summary of exergy destruction in each cycle is given in Table 3. The results show that exergy destruction in the overall system decreases by more $5 \%$ in both cycles. In the AHX cycle, after the improvements, the COP is 1.64 , which is improved by $2.7 \%$, and the exergy efficiency is 0.40 , which is improved by $25 \%$. In the SHX cycle, the COP is 1.74 , which is improved by $0.93 \%$, and the exergy efficiency is 0.35 , which is improved by $1.1 \%$. As shown in Figure 10, exergy efficiency is improved by the distribution of exergy destruction in all components. As a result, COP is higher in the SHX cycle, while exergy efficiency is higher in the AHX cycle. As shown in Figures 11 and 13, the reason is that the total heat recovery rate is larger in the SHX cycle, while the difference between $A_{\text {ed }}$ and $A_{\text {ea }}$ is smaller in the AHX cycle. Thus, when exergy evaluation of the synthesis is performed, we need to consider not only exergy efficiency but also improvement margin. An EUD is a very useful tool because it provides both exergy destruction and margin for reduction at the components comprehensively; in addition, they show there is the presence of a small margin for improvement in both cycles. 


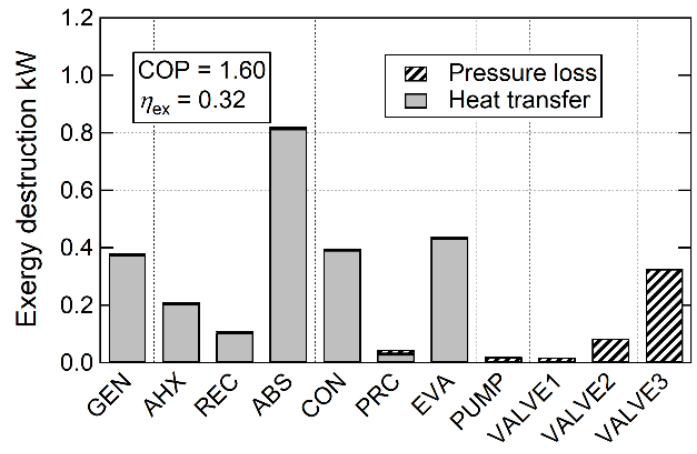

Figure 4. Exergy destruction for the reference system of AHX cycle.

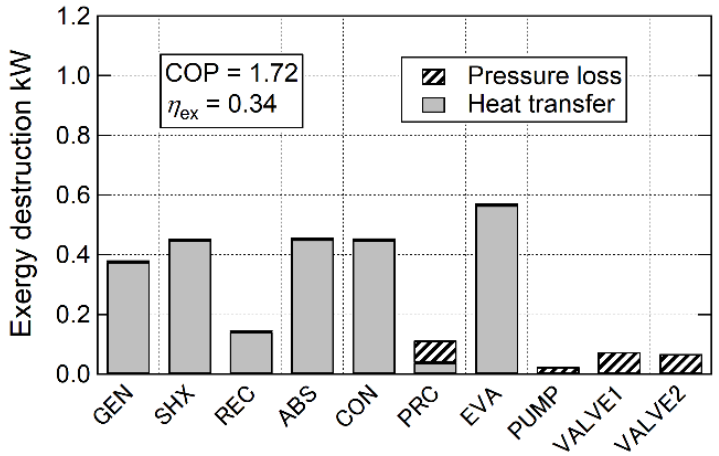

Figure 6. Exergy destruction for the reference system of SHX cycle.

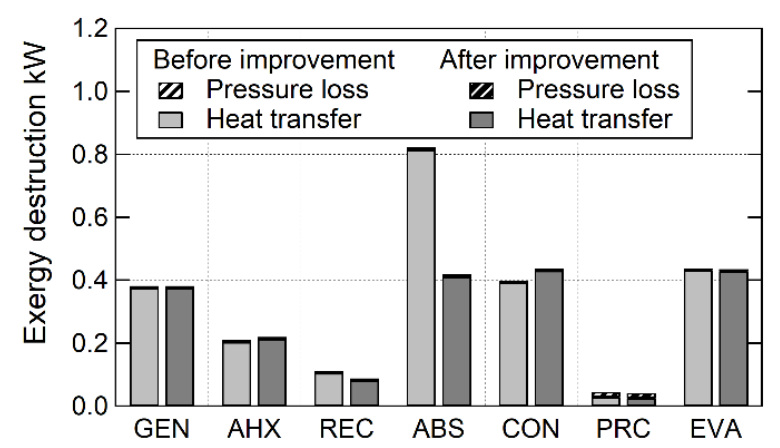

Figure 8. Exergy destruction for AHX cycle after changing hot water outlet temperature in absorber.

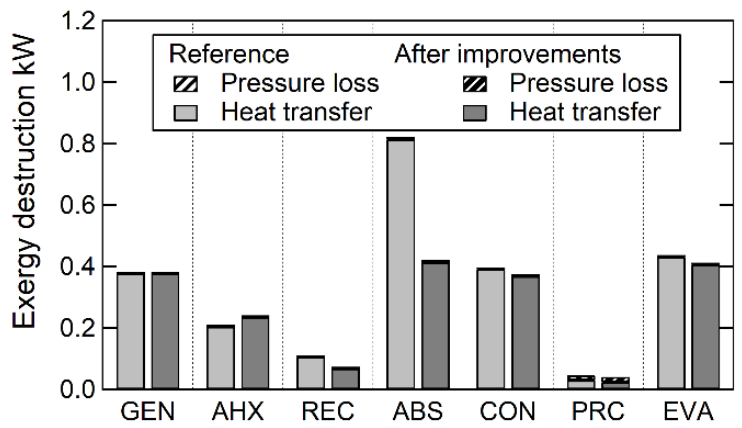

Figure 10. Exergy destruction for AHX cycle after improvement.

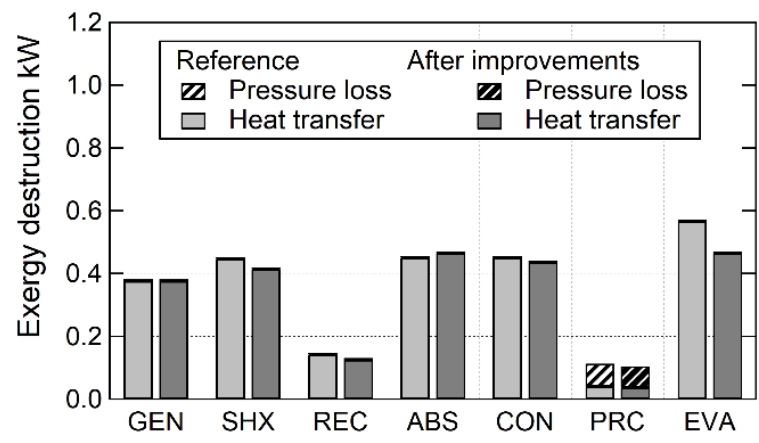

Figure 12. Exergy destruction for SHX cycle after improvement.

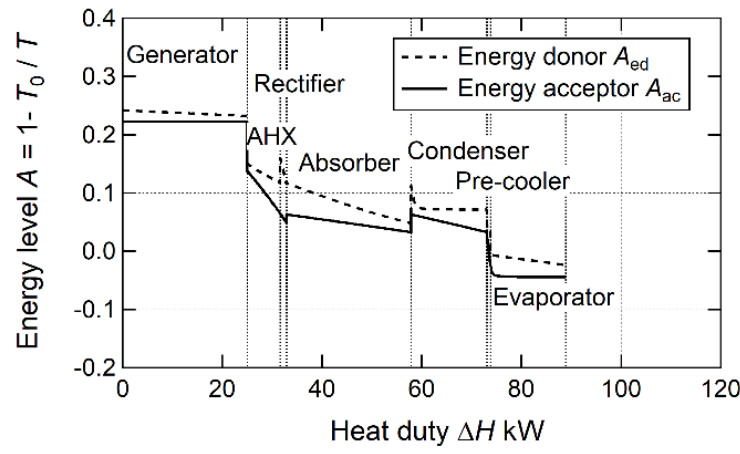

Figure 5. EUD for the reference system of AHX cycle.

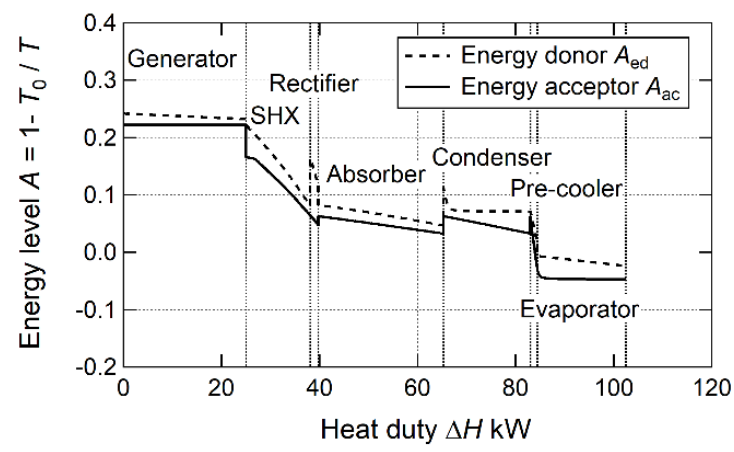

Figure 7. EUD for the reference system of SHX cycle.

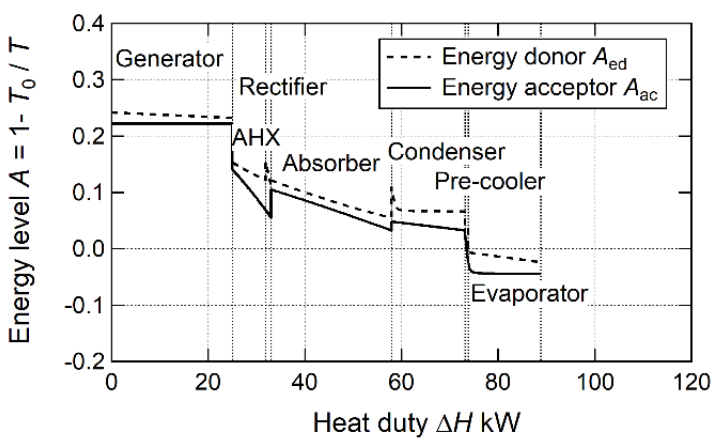

Figure 9. EUD for AHX cycle after changing hot water outlet temperature in absorber.

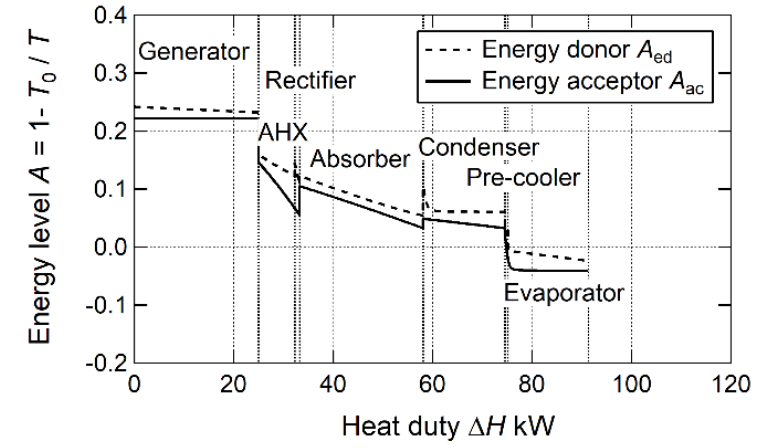

Figure 11. EUD for AHX cycle after improvement.

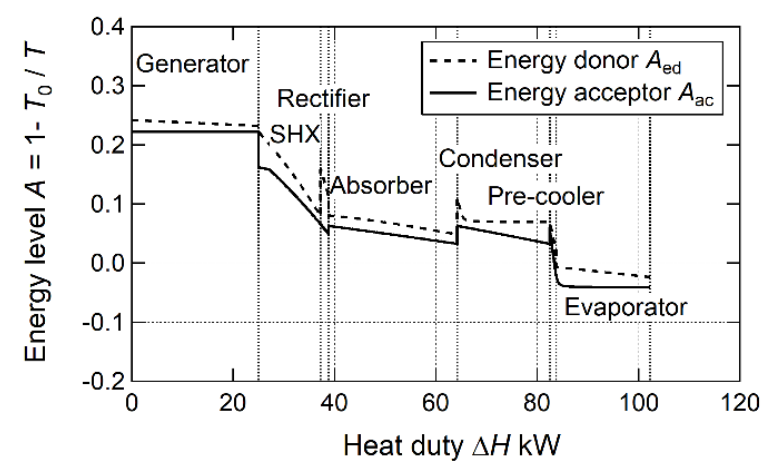

Figure 13. EUD for SHX cycle after improvement. 
Table 3. Summary of exergy destruction before and after improvements in each cycle

\begin{tabular}{|c|c|c|c|c|c|c|}
\hline \multirow[b]{2}{*}{ Items } & \multicolumn{3}{|c|}{ AHX cycle } & \multicolumn{3}{|c|}{ SHX cycle } \\
\hline & $\begin{array}{c}\text { Before } \\
\text { improvement } \\
\text { kW }\end{array}$ & $\begin{array}{c}\text { After } \\
\text { improvement } \\
\text { kW }\end{array}$ & $\%$ change & $\begin{array}{c}\text { Before } \\
\text { improvement } \\
\mathrm{kW}\end{array}$ & $\begin{array}{c}\text { After } \\
\text { improvement } \\
\mathrm{kW}\end{array}$ & $\%$ change \\
\hline Total & 2.38 & 1.92 & -19.3 & 2.55 & 2.39 & -6.16 \\
\hline Generator & 0.377 & 0.377 & 0 & 0.377 & 0.377 & 0 \\
\hline AHX/SHX & 0.205 & 0.236 & 15.3 & 0.449 & 0.415 & -7.44 \\
\hline Rectifier & 0.105 & 0.0683 & -35.1 & 0.143 & 0.126 & -11.6 \\
\hline Absorber & 0.824 & 0.423 & -48.7 & 0.453 & 0.467 & 3.14 \\
\hline Condenser & 0.392 & 0.369 & -5.91 & 0.451 & 0.436 & -3.27 \\
\hline Precooler & 0.0454 & 0.0403 & -11.3 & 0.113 & 0.106 & -6.57 \\
\hline Evaporator & 0.432 & 0.407 & -5.77 & 0.567 & 0.467 & -17.5 \\
\hline $\mathrm{COP}$ & 1.60 & 1.64 & 2.69 & 1.72 & 1.74 & 0.930 \\
\hline$\eta_{\mathrm{ex}}$ & 0.319 & 0.399 & 25.0 & 0.342 & 0.346 & 1.08 \\
\hline
\end{tabular}

\section{Conclusion}

This paper proposes a method for realizing an optimal design of an absorption heat pump cycle efficiently. First, the syntheses of the AHX and SHX cycles are evaluated based on exergy analysis with an EUD. For the AHX cycle, the COP of the reference system is 1.60 and the exergy efficiency is 0.32 , while for the SHX cycle, the COP of the reference system is 1.72 and the exergy efficiency is 0.34 . Thus, COP and exergy efficiency are higher for the SHX cycle. However, the EUDs show that the improvement margin is larger for the AHX cycle. Second, the design/operation optimization of these systems is performed efficiently based on exergy analysis results obtained using an EUD for performance improvement. The effective system parameters for the optimization are selected and improved for reduction of the exergy destruction in the components where dominant exergy destruction occurs, based on an EUD. In the absorber, exergy destruction is reduced by adjusting the operating point to make the temperature gradients at the hot and cold sides coincide. In other components, exergy destruction is reduced by adjusting the design parameters to improve heat transfer performances. In the AHX cycle, after the improvements, the COP is 1.64 and the exergy efficiency is 0.4. In the SHX cycle, the COP is 1.74 and the exergy efficiency is 0.35 . The exergy analysis results show that exergy efficiency is improved by distribution of exergy destruction in all components. As a result, COP is higher in the SHX cycle, while exergy efficiency is higher in the AHX cycle. The EUDs show that this is because the total heat recovery rate is larger in the SHX cycle, while the difference between $A_{\text {ed }}$ and $A_{\text {ea }}$ in the absorber is smaller in the AHX cycle. The EUDs also show that there is a small margin for improvement in both cycles. It is concluded that we can efficiently realize the optimal design of an absorption heat pump cycle system using an EUD. An EUD is a very useful tool because it presents not only exergy destruction but also improvement margin at the heat exchanging components comprehensively and shows the operating point of the system. In addition, it has been confirmed that power recovery devices such as ejectors are effective in improving the system performance of an absorption heat pump [18]. Therefore, future work should explore the method to perform optimization of systems including power recovery devices. Furthermore, a method for determining the optimal system configuration for an absorber heat pump system under the design conditions such as physical properties of refrigerant should be proposed. The above will lead to the establishment of a method for determining the optimal system configuration, the optimal design parameters, and the optimal operation point in a lump.

\section{Acknowledgements}

A part of this work is supported by CREST, the Japan Science and Technology Agency, Grant Number JPMJCR15K5.

\begin{tabular}{|c|c|}
\hline \multicolumn{2}{|c|}{ Nomenclature } \\
\hline A & heat transfer area, $\mathrm{mm}^{2}$, energy level \\
\hline$B$ & spray flow rate \\
\hline$c_{\mathrm{p}}$ & specific heat capacity, $\mathrm{kJ} /(\mathrm{kg} \mathrm{K})$ \\
\hline $\mathrm{COP}$ & coefficient of performance \\
\hline$d$ & diameter, $\mathrm{mm}$ \\
\hline$E_{\mathrm{D}}$ & exergy destruction rate \\
\hline$f$ & friction factor \\
\hline$\dot{G}$ & mass velocity, $\mathrm{kg} /\left(\mathrm{s} \mathrm{mm}^{2}\right)$ \\
\hline$h$ & specific enthalpy, $\mathrm{kJ} / \mathrm{kg}$ \\
\hline$k$ & thermal conductivity, $\mathrm{kW} /(\mathrm{mm} \mathrm{K})$ \\
\hline$L$ & length of tube, $\mathrm{mm}$ \\
\hline$\dot{m}$ & mass flow rate, $\mathrm{kg} / \mathrm{s}$ \\
\hline$N$ & tube number \\
\hline$N_{\text {pass }}$ & pass number \\
\hline $\operatorname{Pr}$ & Prandtl number \\
\hline$\dot{Q}$ & heat exchange rate, $\mathrm{kg} / \mathrm{s}$ \\
\hline$Q u$ & quality \\
\hline $\operatorname{Re}$ & Reynolds number \\
\hline$r$ & fouling factor \\
\hline$s$ & specific entropy, $\mathrm{kJ} /(\mathrm{kg} \mathrm{K})$ \\
\hline$T$ & temperature, ${ }^{\circ} \mathrm{C}$ \\
\hline$U$ & overall heat transfer coefficient, $\mathrm{W} /\left(\mathrm{mm}^{2} \mathrm{~K}\right)$ \\
\hline$v$ & specific volume $\mathrm{m}^{3} / \mathrm{kg}$ \\
\hline$W_{\mathrm{p}}$ & pump power, $\mathrm{kW}$ \\
\hline$z$ & concentration, $\mathrm{kg} / \mathrm{kg}$ \\
\hline \multicolumn{2}{|c|}{ Greek symbols } \\
\hline$\alpha$ & heat transfer coefficient, $\mathrm{kW} /\left(\mathrm{mm}^{2} \mathrm{~K}\right)$ \\
\hline$\Delta E$ & exergy rate, $\mathrm{kW}$ \\
\hline$\Delta H$ & heat duty, kW \\
\hline$\Delta P$ & pressure loss $\mathrm{MPa}$ \\
\hline$\Delta T$ & temperature difference, ${ }^{\circ} \mathrm{C}$ \\
\hline$\lambda$ & vaporization heat, $\mathrm{kJ} / \mathrm{kg}$ \\
\hline$\mu$ & viscosity, $\mathrm{kg} /(\mathrm{mm} \mathrm{s})$ \\
\hline$\rho$ & density, $\mathrm{kg} / \mathrm{mm}^{3}$ \\
\hline$\sigma$ & surface tension $\mathrm{N} / \mathrm{m}$ \\
\hline
\end{tabular}




\begin{tabular}{ll}
\multicolumn{1}{c}{$\eta_{\mathrm{PU}}$} & \multicolumn{1}{c}{ pump efficiency } \\
\multicolumn{1}{c}{$\eta_{\mathrm{R}}$} & rectifying efficiency \\
Subscripts & and superscripts \\
0 & reference environment state \\
$1 \sim 15$ & state point \\
AHX & absorber heat exchanger \\
ABS & absorber \\
CON & condenser \\
ea & energy acceptor (cold stream) \\
ed & energy donor (hot stream) \\
EVA & evaporator \\
GEN & generator \\
H & heat source \\
i & inlet \\
in & inside \\
L & low temperature brine \\
lm & logarithmic mean \\
M & middle temperature hot water \\
o & outlet \\
out & outside \\
PL & pressure loss \\
PRC & precooler \\
pinch & pinch point \\
REC & rectifier \\
sc & subcooling \\
SHX & solution heat exchanger \\
HT & heat transfer \\
v & vapor \\
l & liquid \\
& \\
&
\end{tabular}

\section{References}

[1] R. K. Swartman, V. Ha, C. Swaminathan, "Comparison of ammonia-water and ammonia-sodium thiocyanate as the refrigerant-absorbent in a solar refrigeration system," Solar Energy, 17, 123-127, 1975.

[2] R. Best, C. L. Heard, H. Fernandez, J. Siqueiros, "Developments in geothermal energy in Mexico-Part five: the commissioning of an ammonia/water absorption cooler operating on low enthalpy geothermal energy," Journal of Heat Recovery Systems, 6, 209-216, 1986.

[3] M. A. Siddiqui, "Optimum generator temperatures in four absorption cycles using different sources of energy," Energy Conversion and Management, 34, 251266, 1993.

[4] J. F. Seara, A. Vales, M. Vazquez, "Heat recovery system to power an onboard $\mathrm{NH}_{3}-\mathrm{H}_{2} \mathrm{O}$ absorption refrigeration plant in trawler chiller fishing vessels," Applied Thermal Engineering, 18, 1189-1205, 1998.

[5] W. Wei, W. Baolong, S. Wenxing, L. Xianting, “An overview of ammonia-based absorption chillers and heat pumps," Renewable and Sustainable Energy Reviews, 31, 681-707, 2014.

[6] K. E. Herold, R. Radermacher, S.A. Klein, Absorption chillers and heat pumps, $2^{\text {nd }} E d$. Boca Raton: CRC
Press, 2016.

[7] R. Ventas, A. Lecuona, A. Zacarías, M. Venegas, "Ammonia-lithium nitrate absorption chiller with an integrated low-pressure compressor booster cycle for low driving temperatures," Applied Thermal Engineering, 30, 1351-1359, 2010.

[8] C. Vereda, R. Ventas, A. Lecuona, M. Venegas, "Study of an ejector-absorption refrigeration cycle with an adaptable ejector nozzle for different working conditions," Applied Thermal Engineering, 97, 305312, 2012.

[9] C. A. Frangopoulos, M. R. von Spakovsky, E. Sciubba, "A brief review of methods for design and synthesis optimization of energy systems," Applied Thermal Engineering, 5, 151-160, 2002.

[10] K. Seki, K. Takeshita, Y. Amano, "Development of complex energy systems with absorption technology by combining elementary processes," Energies, 12, 495, 2019.

[11] Inoue, N. (2005). Studies on the Characteristics of Absorption Cycles and their Applications (Doctoral dissertation), University Waseda, Doctor of Engineering, $\mathrm{Ph}$. D.

[12] Y. T. Kang, W. Chen, R. N. Christensen, "Development of design model for a rectifier in GAX absorption heat pump systems," ASHRAE Transactions, 102, 963-972, 1996.

[13] M. Ishida, Creation of energy system, Tokyo: Ohmsha, 2004.

[14] G. Wall, C. C. Chuang, M. Ishida, "Exergy study of the kalian cycle," Analysis and Design of Energy Systems: Analysis of Industrial Processes, 10, 73-77, 1989.

[15] T. Srinophakun, S. Laowithayangkul, M. Ishida, "Simulation of power cycle with energy utilization diagram," Energy Conversion and Management, 42, 1437-1456, 2001.

[16] H. Hattori, H. Matsumoto, and Y. Amano, "Design of an Ejector-Absorption Heat Pump based on Entropy Generation Minimization," in ECOS 2017: Proceeding of the 30th International Conference on Efficiency, Cost, Optimization, Simulation and Environmental Impact of Energy Systems, San Diego, California, USA, 2017.

[17] H. Obana, Handbook for designing of heat exchanger, $2^{\text {nd }} E d$. Tokyo: Engineering book Inc., 2000.

[18] H. Matsumoto, H. Hattori, and Y. Amano, "Investigation of absorption heat pump cycle driven by low temperature waste heat," in PRTEC 2016: Proceedings of the First Pacific Rim Thermal Engineering Conference, Hawaii's Big Island, USA, 2016. 